\title{
Synthesis, Crystal Growth, Spectroscopic and Electrical Properties of 5-tert-Butyl-1,2,3-trinitrobenzene
}

\author{
S. Sahaya Jude Dhas, ${ }^{1}$ M. Muralidhar Nayak, ${ }^{2}$ S. Jerome Das, ${ }^{1}$ and S. A. Martin Britto Dhas ${ }^{3}$ \\ ${ }^{1}$ Department of Physics, Loyola College, Chennai 600034, India \\ ${ }^{2}$ Spectroscopy/Analytical Test Facility, Indian Institute of Science, Bangalore 560012, India \\ ${ }^{3}$ Department of Physics, Sacred Heart College, Tirupattur 635601, India
}

Correspondence should be addressed to S. A. Martin Britto Dhas; brittodhas@gmail.com

Received 10 January 2013; Accepted 26 January 2013

Academic Editor: Iwan Kityk

Copyright (C) 2013 S. Sahaya Jude Dhas et al. This is an open access article distributed under the Creative Commons Attribution License, which permits unrestricted use, distribution, and reproduction in any medium, provided the original work is properly cited.

5-tert-Butyl-1,2,3-trinitrobenzene (TBTB) was synthesized and characterized by NMR so as to confirm the structure. Single crystals were obtained from methanol by solvent evaporation technique at room temperature. Optically transparent single crystals with dimension up to $17 \times 4 \times 3 \mathrm{~mm}^{3}$ have been grown by submerged seed solution method within a period of 30 days. The modes of vibration of different molecular groups present in the title compound were identified by FTIR and FT-Raman spectral analyses, and it was found with the tabulation that both of the spectral vibrations are very close to each other confirming the existence of specific functional groups in the crystal. Optical behaviour of the crystal was analyzed by UV-Vis absorption studies, and the value of the optical band gap energy $\left(E_{g}\right)$ of the crystal has been determined using the optical absorption spectrum. The dielectric behaviour and $\mathrm{AC}$ conductivity of the grown crystals were also analyzed, and it is shown that both properties vary with respect to frequency and do not vary in accordance with temperature.

\section{Introduction}

Nitroaromatics form an important group of recalcitrant xenobiotics [1]. The majority of such types of compounds are industrial chemicals such as explosives, dyes, polyurethane foams, herbicides, insecticides, and solvents. Compounds of trinitrate can be used to treat and prevent an angina attack [2]. Also, organic crystals of nitrophenol family play a prominent role in nonlinear optical area due to their superior qualities such as high laser damage threshold, wide transparency windows, and extended thermal stability. As a consequence, a large number of nitrophenol families of crystals have been already grown and reported [3-13]. In a particular case, the laser damage thresholds of nonlinear optical crystals of sodium p-nitrophenolate dehydrate are $11.16 \pm 0.28 \mathrm{GW} \mathrm{cm}^{-2}$ and $1.25 \pm 0.02 \mathrm{GW} \mathrm{cm}^{-2}$ for $1064 \mathrm{~nm}$ and $532 \mathrm{~nm}$ laser wavelengths, respectively [14, 15], while the laser damage threshold of standard potassium dihydrogen phosphate (KDP) is $0.2 \mathrm{GW} \mathrm{cm}^{-2}$ [16].
Also, nitrobenzene compounds possess high contribution of anharmonic electron-phonon interaction and can be used as a material for the fast-respond degenerate four-wave mixing [17]. Hence, it is useful to analyze the spectroscopic and physical properties of such type of nitrophenol family of compounds. 5-tert-Butyl-1,2,3-trinitrobenzene (ТВTB) is yet another compound which has been synthesized and characterized for the present work. Even though there is a lot of information available about the different derivatives of nitrobenzene in the literature; to our knowledge, there are no details found regarding the vibration and optical and electrical studies for this particular compound (TBTB). So we made an attempt to investigate the same. We have also grown bulk crystals of the title compound for the first time and characterized the same with the vibrational analyses (FTIR, FT-Raman spectroscopy) and electronic spectra (UVVis). The dielectric studies were also carried out so as to know the optical and electrooptical behaviour of the crystal. 


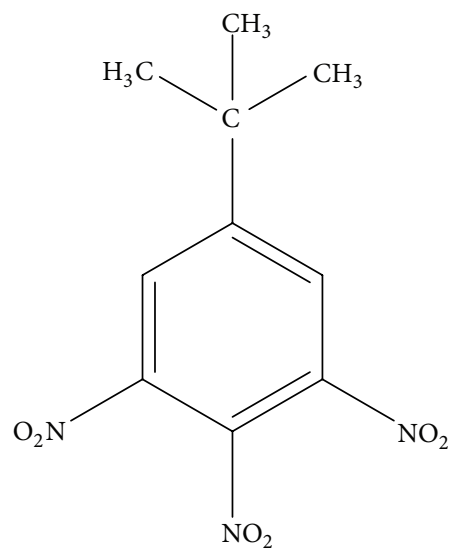

FIgURE 1: The chemical structure of 5-tert-butyl-1,2,3-trinitrobenzene.

\section{Experimental Procedure}

2.1. Material Synthesis. 5-tert-Butyl-1,2,3-trinitrobenzene was synthesized as per literature procedure [18]. $10 \mathrm{~g}$ of 4-tert-butylphenol was dissolved in $50 \mathrm{~mL}$ of glacial acetic acid. This solution was added dropwise with constant stirring to a mixture of $1: 2$ ratios of nitric acid and glacial acetic acid while cooling. This mixture, after attaining the room temperature, was then poured onto crushed ice. The resulting yellow solid was filtered off, redissolved in chloroform. Then this yellow coloured solution was washed five times with water to remove the water soluble impurities. Afterwards, the organic phase was dried with $\mathrm{Na}_{2} \mathrm{SO}_{4}$ and the solvent was removed under reduced pressure. The residue was further purified by silica column chromatography, ethyl acetate/hexane (1:6) as elute. This gives 5-tert-butyl-1,2,3trinitrobenzene as a yellow powder, and the chemical structure is shown in Figure 1.

NMR spectra $\left({ }^{1} \mathrm{H}\right.$ and $\left.{ }^{13} \mathrm{C}\right)$ were recorded for this yellow crystalline powder so as to get information about the carbon hydrogen framework in the molecule with a Bruker AMX 400 spectrometer with tetramethylsilane as the internal standard and $\mathrm{CDCl}_{3}$ as the solvent. The recorded spectra were shown in Figures 2 and $3 .{ }^{1} \mathrm{H} \mathrm{NMR}\left(400 \mathrm{MHz}, \mathrm{CDCl}_{3}\right): \delta 8.33(\mathrm{~s}$, $2 \mathrm{H}$, benzene ring $\mathrm{CH}), 1.38$ ( $\mathrm{m}, 9 \mathrm{H}$ tert butyl $\mathrm{CH})$. NMR shows that the compound is pure without any impurities. The product was further purified by repeated recrystallization.

2.2. Crystal Growth. The title compound is a yellowish crystalline powder and has a molecular formula $\mathrm{C}_{10} \mathrm{H}_{12} \mathrm{~N}_{2} \mathrm{O}_{5}$ with molecular weight $240.21 \mathrm{~g} \mathrm{~mol}^{-1}$. The saturated solution of the title compound was prepared at room temperature with methanol as the solvent. The solution was stirred well for about half an hour using a magnetic stirrer to ensure homogeneous temperature and concentration over the entire volume of the solution. The prepared solution was filtered with a microporous filter paper and transferred to crystal growth vessel, and crystallization was allowed to take place by slow evaporation under room temperature. Small crystals were obtained in a time of one week. From the previously

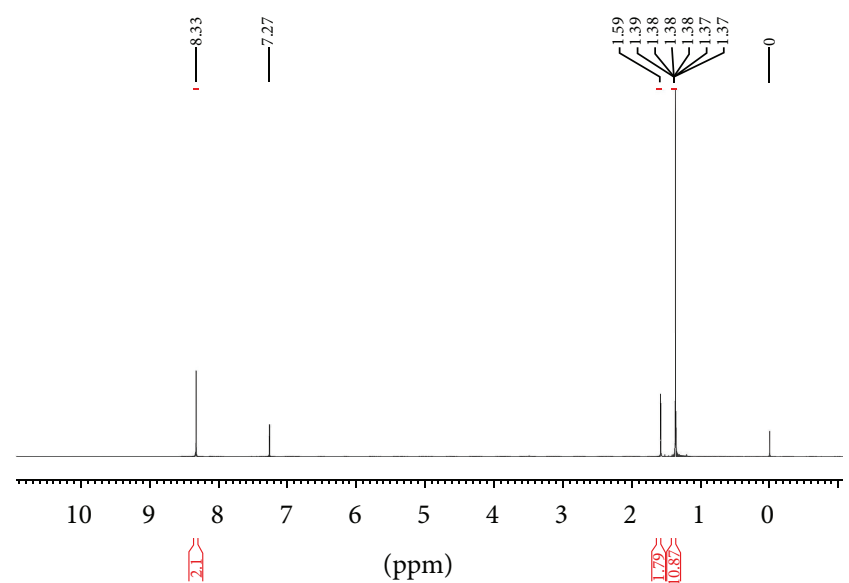

FIgURE 2: ${ }^{1} \mathrm{H}$ NMR of TBTB.

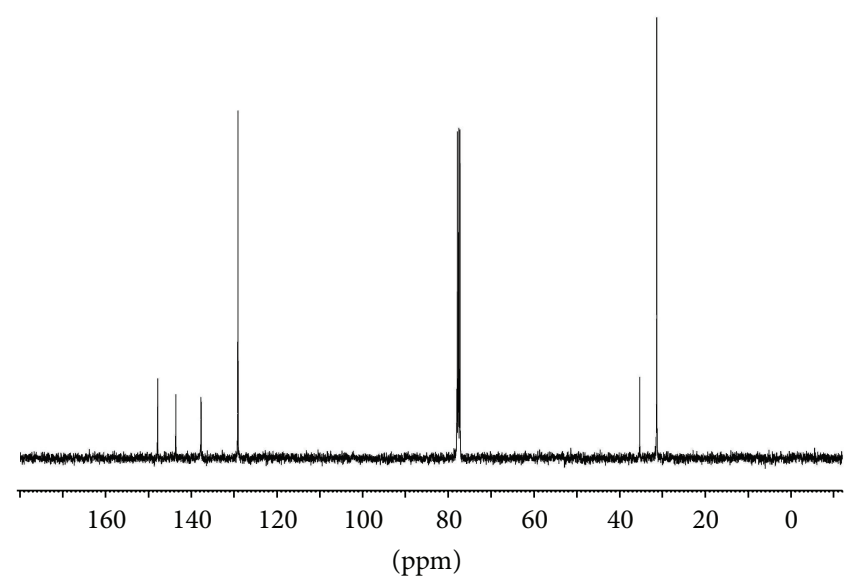

Figure $3:{ }^{13} \mathrm{C}$ NMR of TBTB.

mentioned crystals, well-shaped and transparent crystals were selected as seeds, and the remaining crystals were powdered and used as raw material for bulk crystal growth. The powdered material was added gradually in the solvent (methanol) till it completely dissolved so as to obtain saturated solution at room temperature $\left(30^{\circ} \mathrm{C}\right)$. In order to obtain supersaturation, the temperature of the solution was raised by $2^{\circ} \mathrm{C}$ above the room temperature, and the solute was added till it dissolved completely and was stirred for 30 minutes to obtain a homogeneous solution. The supersaturated solution was filtered, and the selected seed crystal was placed carefully at the bottom of a beaker and kept covered for controlled evaporation to take place. After about 30 days, transparent single crystal of good quality with approximate size of 17 $\times 4 \times 3 \mathrm{~mm}^{3}$ was obtained. The grown crystal is optically transparent as shown in Figure 4.

\section{Spectroscopic Studies}

3.1. FT-Raman Spectral Analysis. The FT-Raman spectral measurements were made with a model RFS 100/S Bruker instrument. Nd:YAG laser beam of wavelength $1064 \mathrm{~nm}$, the output power being $20 \mathrm{~mW}$, was used. The spectrum was 


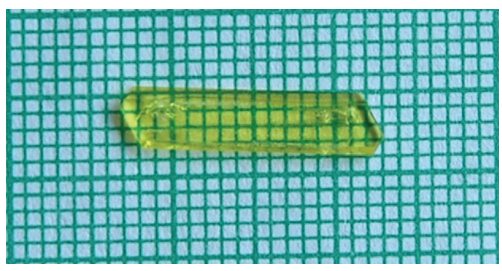

FIGURE 4: Photograph of as-grown TBTB single crystal.

TABLE 1: The comparison of FT-Raman and FT-Infrared spectral data of TBTB and their tentative assignment.

\begin{tabular}{|c|c|c|}
\hline $\operatorname{Raman} \bar{v}\left(\mathrm{~cm}^{-1}\right)$ & Infrared $\bar{v}\left(\mathrm{~cm}^{-1}\right)$ & Tentative assignment \\
\hline & $3242 b$ & $\mathrm{C}-\mathrm{H}$ str \\
\hline $3087 \mathrm{w}$ & $3084 \mathrm{w}$ & $\mathrm{C}-\mathrm{H}$ str \\
\hline $2973 \mathrm{~m}$ & $2960 \mathrm{~s}$ & $\mathrm{CH}_{3}$ asym str \\
\hline \multirow[t]{3}{*}{$2911 \mathrm{~m}$} & & C-H str \\
\hline & $2860 \mathrm{w}$ & $\mathrm{C}-\mathrm{H}$ str \\
\hline & $1628 \mathrm{~m}$ & $\mathrm{~N}=\mathrm{O}$ str \\
\hline $1593 \mathrm{w}$ & $1597 \mathrm{w}$ & Ring breathing \\
\hline $1531 \mathrm{~m}$ & $1526 \mathrm{~s}$ & C-H deform \\
\hline $1448 \mathrm{w}$ & $1480 \mathrm{~m}$ & $\mathrm{C}-\mathrm{H}$ def, s.c. ring str \\
\hline 1415 w & $1418 \mathrm{~m}$ & $\begin{array}{l}\mathrm{C}-\mathrm{H} \text { in-plane } \\
\text { bending }\end{array}$ \\
\hline $1364 s$ & $1367 \mathrm{~m}$ & $\mathrm{C}-\mathrm{N}$ str \\
\hline $1321 \mathrm{~s}$ & $1314 \mathrm{~s}$ & Ring breathing \\
\hline $1304 \mathrm{~s}$ & & $\mathrm{~N}=\mathrm{O}_{2}$ sym str \\
\hline $1264 \mathrm{~s}$ & $1254 \mathrm{~m}$ & $\mathrm{C}-\mathrm{N}$ str \\
\hline \multirow[t]{2}{*}{$1162 \mathrm{~s}$} & $1147 \mathrm{w}$ & C-H i.p. def \\
\hline & $1104 \mathrm{w}$ & C-H i.p. def \\
\hline $922 \mathrm{~m}$ & $915 \mathrm{~m}$ & $\mathrm{C}-\mathrm{C}$ str \\
\hline $827 \mathrm{~m}$ & $831 \mathrm{~m}$ & C-H o.p. bending \\
\hline $726 \mathrm{~m}$ & $712 \mathrm{~m}$ & C-H o.p. def, $\mathrm{NO}_{2}$ def \\
\hline \multirow{4}{*}{$528 \mathrm{w}$} & $646 \mathrm{~m}$ & $\begin{array}{l}\text { C-H o.p. bending, } \\
\text { C-C-C o.p. def }\end{array}$ \\
\hline & $590 \mathrm{~m}$ & C-C-N i.p. def \\
\hline & $514 \mathrm{w}$ & C-C-C i.p. def \\
\hline & $427 \mathrm{w}$ & $\mathrm{C}-\mathrm{CN}$ i.p. bending \\
\hline
\end{tabular}

Asym: asymmetric; def: deformation; i.p.: in-plane; i.ph.: in-phase; $\mathrm{m}$ : medium; op: out-of plane; s: strong; str: stretch; sym: symmetric; v: very; w: weak; s.c: semi circle; b: broad.

recorded for a range of 4000 to $500 \mathrm{~cm}^{-1}$ with a spectral resolution of $4 \mathrm{~cm}^{-1}$. Raman spectroscopy is an inelastic photon scattering between a laser beam and a molecule. Raman scattering occurs when the vibrational motion produces an induced dipole moment or change in the polarizability of the molecule [19]. The recorded FT-Raman spectra are shown in Figure 5.

In the higher frequency region, the weak peak at $3087 \mathrm{~cm}^{-1}$ is due to $\mathrm{C}-\mathrm{H}$ stretching and the medium peak at $2973 \mathrm{~cm}^{-1}$ is assigned to $\mathrm{CH}_{3}$ asymmetric stretching. The medium peak at $2911 \mathrm{~cm}^{-1}$ confirms the existence of $\mathrm{C}-\mathrm{H}$

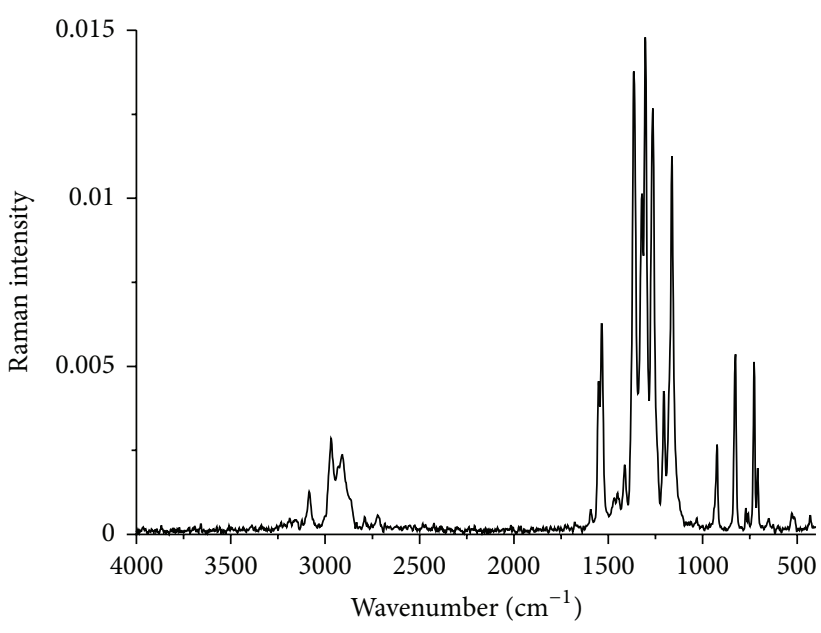

Figure 5: FT-Raman spectrum of TBTB.

stretching and at $1531 \mathrm{~cm}^{-1}$ establishes the presence of C$\mathrm{H}$ deformation. The strong peak at $1364 \mathrm{~cm}^{-1}$ is because of C-N stretching and at $1304 \mathrm{~cm}^{-1}$ is ascribed to $\mathrm{N}=\mathrm{O}_{2}$ asymmetric stretching. The strong peak at $1264 \mathrm{~cm}^{-1}$ illustrates the presence of $\mathrm{C}-\mathrm{N}$ stretching and at $1162 \mathrm{~cm}^{-1}$ is assigned to $\mathrm{C}-\mathrm{H}$ in-plane deformation. The medium band at $922 \mathrm{~cm}^{-1}$ is attributed to the presence of C-C stretching. The medium peak at $827 \mathrm{~cm}^{-1}$ is assigned to $\mathrm{C}-\mathrm{H}$ out-of-plane bending and at $726 \mathrm{~cm}^{-1}$ is assigned for the presence of $\mathrm{NO}_{2}$ deformation and $\mathrm{C}-\mathrm{H}$ out-of-plane deformation. $\mathrm{C}-\mathrm{C}-\mathrm{C}$ inplane deformation is located at the weak peak of $528 \mathrm{~cm}^{-1}$.

3.2. FTIR Spectral Analysis. The FTIR spectrum of the grown TBTB crystals was recorded using FTIR spectrometer (Bruker alpha) in the region of 4000 to $400 \mathrm{~cm}^{-1}$ with a spectral resolution of $4 \mathrm{~cm}^{-1}$. The absorption of IR radiation causes various bands in a spectrum which can be treated as the finger print of different modes of vibration of a molecule, and it clearly exhibits the presence of various functional groups present in a compound. The infrared absorption arises when the vibrational motion produces a change in the permanent dipole moment of the molecule [19]. The recorded FTIR spectrum is shown in Figure 6.

In the higher frequency region, the broad peak at $3242 \mathrm{~cm}^{-1}$ and the weak peak at $3084 \mathrm{~cm}^{-1}$ denote the occurrence of C-H stretching and the strong peak at $2960 \mathrm{~cm}^{-1}$ is assigned to $\mathrm{CH}_{3}$ asymmetric stretching. The medium absorption peak at $1628 \mathrm{~cm}^{-1}$ confirms the existence of $\mathrm{N}=\mathrm{O}$ stretching. The strong peak at $1526 \mathrm{~cm}^{-1}$ establishes the presence of $\mathrm{C}-\mathrm{H}$ deformation. The medium peak at $1480 \mathrm{~cm}^{-1}$ is due to $\mathrm{C}-\mathrm{H}$ deformation and semicircle ring stretching, and also the medium peak at $1418 \mathrm{~cm}^{-1}$ is assigned to $\mathrm{C}-\mathrm{H}$ in-plane bending. The strong peak at $1314 \mathrm{~cm}^{-1}$ is ascribed to ring breathing. The absorption medium peak at $1254 \mathrm{~cm}^{-1}$ illustrates the presence of $\mathrm{C}-\mathrm{N}$ stretching. The weak absorption peak at $1147 \mathrm{~cm}^{-1}$ is assigned to $\mathrm{C}-\mathrm{H}$ in-plane deformation. The medium band at $915 \mathrm{~cm}^{-1}$ is attributed to the presence of $\mathrm{C}-\mathrm{C}$ stretching. The medium peak at $831 \mathrm{~cm}^{-1}$ is assigned to $\mathrm{C}-\mathrm{H}$ 


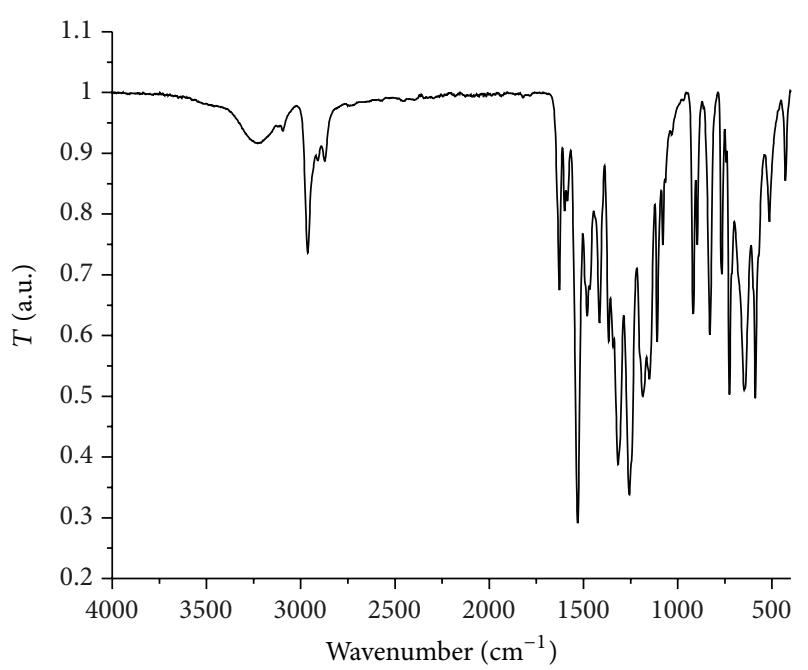

FIGURE 6: FTIR spectrum of TBTB.

out-of-plane bending and at $712 \mathrm{~cm}^{-1}$ is due to the presence of $\mathrm{NO}_{2}$ deformation and $\mathrm{C}-\mathrm{H}$ out-of-plane deformation. C$\mathrm{C}-\mathrm{N}$ in-plane deformation is identified by the medium peak at $590 \mathrm{~cm}^{-1}$. The weak peak at $514 \mathrm{~cm}^{-1}$ represents $\mathrm{C}-\mathrm{C}-\mathrm{C}$ in-plane deformation, and $\mathrm{C}-\mathrm{CN}$ in-plane bending is located at the weak peak of $427 \mathrm{~cm}^{-1}$. The comparison of FT-Raman and infrared spectral analyses is shown in Table 1.

3.3. UV-Vis-IR Spectral Studies. Figure 7 shows the absorption spectrum obtained for the title compound in solution in the region between 200 and $700 \mathrm{~nm}$, covering the entire UV, visible, and near infrared region. The absorbance at $350 \mathrm{~nm}$ is due to $n-\pi^{*}$ electronic excitation in the $\mathrm{NO}_{2}$ group of trinitrobenzene. The absorption coefficient is dependent on photon energy, and it was analyzed in the absorption regions so as to obtain the detailed information about the energy band gap of the compound. The absorption coefficient and photon energy can be related by the equation $[20,21]$

$$
(\alpha h v)^{2}=A\left(h v-E_{g}\right),
$$

where $E_{q}$ is the energy band gap of the compound, $A$ is a constant that depends on transition probability, and $\alpha$ is the absorption coefficient. The variations of $(\alpha h v)^{2}$ against $h v$ in the fundamental absorption region are plotted as shown in Figure 8. The extrapolation of the straight line down to $(\alpha h v)^{2}$ gives the band gap energy of the crystal. The band gap of TBTB crystal was found to be $3.18 \mathrm{eV}$.

\section{Dielectric Studies}

Dielectric studies for the grown 5-tert-butyl-1,2,3-trinitrobenzene single crystals were carried out using HIOKI 353250 LCR HITESTER in the frequency region $50 \mathrm{~Hz}-5 \mathrm{MHz}$ (with an accuracy of $|\mathbf{Z}|: \pm 0.08 \%$ rdg., $\boldsymbol{\theta}: \pm 0.05^{\circ}$ ). A quality sample of the crystal of uniform cross section $3 \times 2 \mathrm{~mm}^{2}$ and $1.5 \mathrm{~mm}$ thickness was placed between the two copper electrodes acting as a parallel plate capacitor. Silver paint was

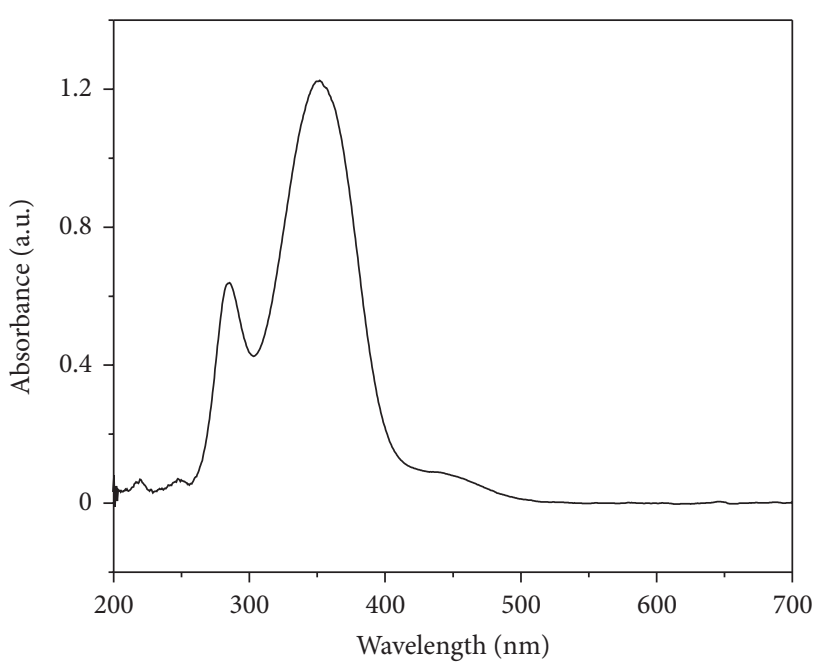

FIgURE 7: UV-Vis spectrum of TBTB.

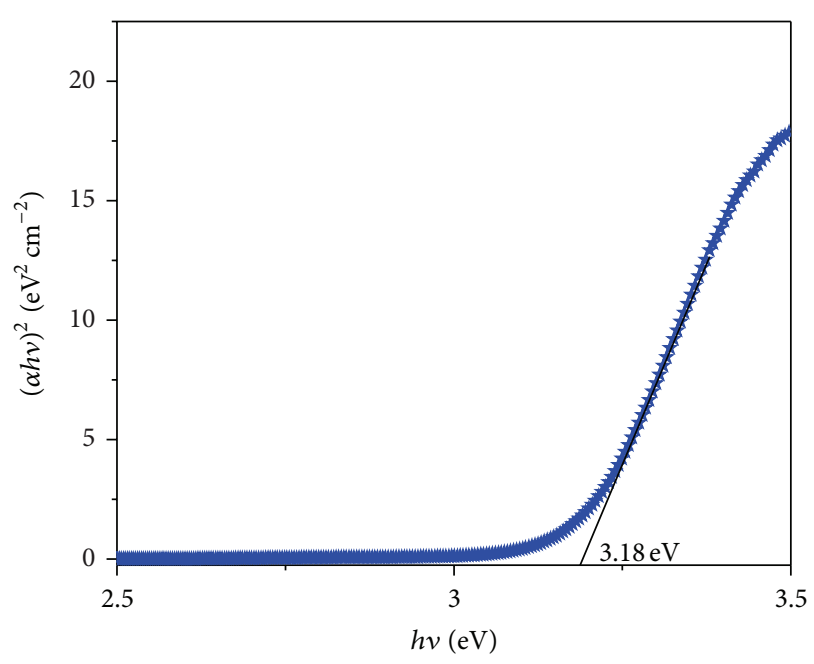

FIgURE 8: Plot of $(\alpha h v)^{2}$ versus $h v$ for TBTB crystals.

coated on the surface of the sample so as to make a steady electrical contact. The dielectric constant $\left(\varepsilon_{r}\right)$ was calculated using the relation

$$
\varepsilon_{r}=\frac{C d}{\varepsilon_{0} A},
$$

where $C$ is the capacitance, $d$ is the thickness of the crystal, $\varepsilon_{0}$ is the permittivity of free space, and $A$ is the area of the crystal. The dielectric properties can very well be related with electrooptic properties of the crystal [22]. The variation of calculated dielectric constant and dielectric loss with respect to $\log$ frequency for three different temperatures $\left(40^{\circ}, 50^{\circ}\right.$, and $60^{\circ}$ ) is shown in Figures 9 and 10, respectively. Both the dielectric constant and the dielectric loss are decreasing rapidly and get saturated when increasing the frequency. This is a normal dielectric behaviour [23]. This can be understood on the basis that the mechanism of polarization is similar to that of the conduction process. When the crystal is subjected to external electric field the dipoles align themselves in the 


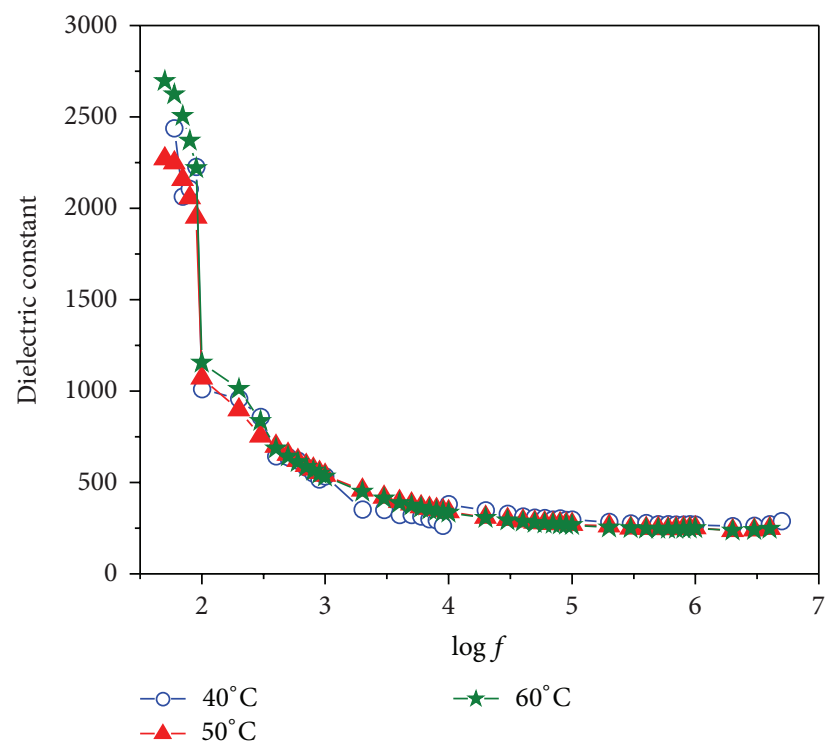

Figure 9: $\log f$ versus dielectric constant for different temperatures.

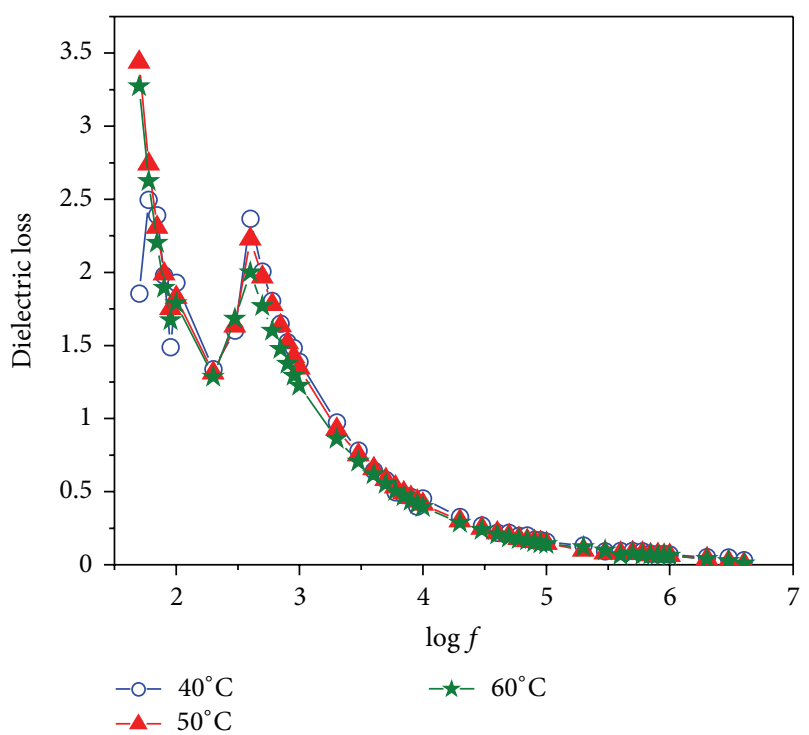

Figure 10: $\log f$ versus dielectric loss for different temperatures.

direction of the field causing a steady polarization which is due to the promotion of relative displacement between the electrons and the lattice ions, and this particular state is maintained by the crystal as long as the value of the frequency is low. At the higher region of frequency, the space charges cannot sustain and cannot comply with the external field. Consequently, the value of polarization decreases rapidly with an immediate effect of a drastic fall in the value of the dielectric constant of the crystal.

\section{AC Conductivity}

AC conductivity is one of the studies done on solids in order to characterize the bulk resistance of the crystalline sample

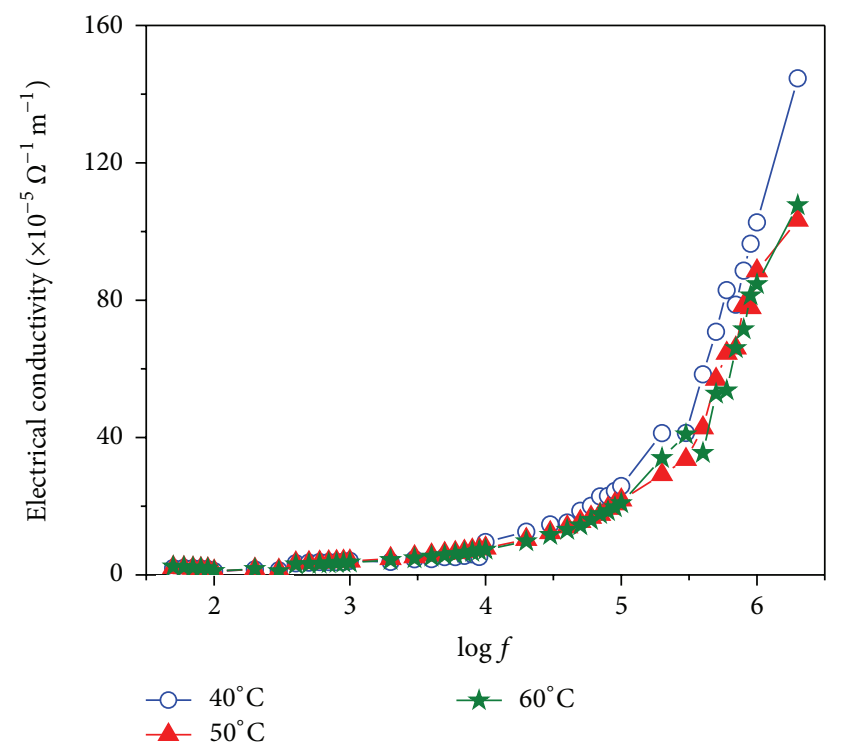

Figure 11: $\log f$ versus electrical conductivity.

and it is quite important to know the ac conductivity of the material so as to explore its effectiveness to be used as a dielectric. The ac conductivity of the sample was calculated using the formula [24]

$$
\sigma_{\mathrm{ac}}=\varepsilon_{0} \varepsilon_{r} \omega \tan \delta,
$$

where $\omega$ is the angular frequency $(\omega=2 \pi \nu)$. The plot of electrical conductivity versus frequency for different temperatures is shown in Figure 11. The conductivity is almost zero up to $10 \mathrm{kHz}$ of frequency, and it starts increasing beyond that value. The low value of electrical conductivity may be due to the decrease in mobility of the charge carriers due to ionic size which leads to the change in electronic band structure. At higher frequencies, the ac conductivity of the sample increases which reveals that the electrical conductivity is proportional to the mobility and carrier concentration. The dielectric and ac conductivity studies reveal that the previously mentioned properties are dependent on frequency but independent of temperature.

\section{Conclusion}

The compound of 5-tert-butyl-1,2,3-trinitrobenzene was synthesized, and the structure of the compound was confirmed with the help of ${ }^{1} \mathrm{H}$ and ${ }^{13} \mathrm{C}$ NMR spectra. Transparent single crystals of TBTB have been grown successfully by submerged seed solution method in methanol at about a period of a month's time. FTIR and FT-Raman spectra reveal the mode of vibrations of different functional groups present in the title compound, and the tabulated values of both of the spectra agree very well with each other to a very close extent so that different molecular groups present in TBTB are confirmed. Optical transmission studies show that the title compound is optically transparent in the entire visible region with a lower cutoff below $400 \mathrm{~nm}$. The calculated value of the optical band gap energy $\left(E_{g}\right)$ of the crystal is found to be $3.18 \mathrm{eV}$. The 
experimental results show that the dielectric property and the conductivity of TBTB are dependent on frequency but independent of temperature.

\section{References}

[1] Z. Snellinx, A. Nepovím, S. Taghavi, J. Vangronsveld, T. Vanek, and D. Van der Lelie, "Biological remediation of explosives and related nitroaromatic compounds," Environmental Science and Pollution Research, vol. 9, no. 1, pp. 48-61, 2002.

[2] M. Peters, BMA A-Z Family Medical Encyclopedia, 2004.

[3] R. N. Rai, P. Ramasamy, and C. W. Lan, "Synthesis and crystal growth of binary organic NLO material UNBA," Journal of Crystal Growth, vol. 235, no. 1-4, pp. 499-504, 2002.

[4] A. M. Petrosyan, H. A. Karapetyan, A. A. Bush, and R. P. Sukiasyan, "Crystal structure and characterization of L-arginine dichloride monohydrate and L-arginine dibromide monohydrate," Materials Chemistry and Physics, vol. 84, no. 1, pp. 79-86, 2004.

[5] S. C. Sabarwal and Sangeetha, "Effect of sodium doping on thermoluminescence and optical properties of barium borate $\left(\mathrm{BaB}_{2} \mathrm{O}_{4}\right)$ single crystals," Journal of Crystal Growth, vol. 187, no. 2, pp. 253-258, 1998.

[6] J. D. Bierlin, L. K. Cheng, Y. Wang, and W. T. Company, "Linear and nonlinear optical properties of 3-methyl-4-methoxy-4' nitrostilbene single crystals," Applied Physics Letters, vol. 56, pp. 423-425, 1990.

[7] S. Natarajan, M. Umamaheswaran, J. Kalyana Sundar, J. Suresh, and S. A. Martin Britto Dhas, "Structural, spectroscopic and nonlinear optical studies on a new efficient organic donor-acceptor crystal for second harmonic generation: LThreoninium picrate," Spectrochimica Acta A, vol. 77, no. 1, pp. 160-163, 2010.

[8] C. Vesta, R. Uthrakumar, G. Vinitha, A. Ramalingam, and S. Jerome Das, "Studies on novel single crystals of tri-nitrophenol methyl p-hydroxybenzoate," Journal of Crystal Growth, vol. 311, no. 16, pp. 4016-4021, 2009.

[9] J. Yabu zaki, Y. Takahashi, H. Adiuchi, and Y. Mori.T. Sasaki, "High-quality crystal growth and characterization of organic nonlinear optical crystal: 4-dimethylamino-N-methyl4-stilbazolium tosylate (DAST)," Bulletin of Materials Science, vol. 22, no. 1, pp. 11-13, 1999.

[10] B. F. Levine, C. G. Bethea, C. D. Thurmond, R. T. Lynch, and J. L. Borstein, "An organic crystal with an exceptionally large optical second-harmonic coefficient: 2-methyl-4-nitroaniline," Journal of Applied Physics, vol. 50, pp. 2523-2527, 1979.

[11] P. Kerkoc, M. Zgonik, K. Sutter, C. H. Bosshand, and P. Gunter, "Optical and nonlinear optical properties of 4-(N, $\mathrm{N}$-dimethylamino)-3-acetamidonitrobenzene single crystals," Applied Physics Letters, vol. 54, pp. 2062-2064, 1989.

[12] R. Ramesh Babu, N. Vijayan, M. Gunasekaran, R. Gopalakrishnan, and P. Ramasamy, "Studies on organic single crystal: 2-amino-5-chlorobenzophenone (2A-5CB)," Journal of Crystal Growth, vol. 265, no. 1-2, pp. 290-295, 2004.

[13] Y. Goto, A. Hayashi, Y. Kimura, and M. Nakayama, "Second harmonic generation and crystal growth of substituted thienyl chalcone," Journal of Crystal Growth, vol. 108, no. 3-4, pp. 688698, 1991.

[14] S. Vanishri, J. N. Babu Reddy, H. L. Bhat, and S. Ghosh, "Laser damage studies in nonlinear optical crystal sodium pnitrophenolate dihydrate," Applied Physics B, vol. 88, no. 3, pp. 457-461, 2007.
[15] L. N. Wang, X. Q. Wang, G. H. Zhang et al., "Single crystal growth, crystal structure and characterization of a novel crystal: l-arginine 4-nitrophenolate 4-nitrophenol dehydrate (LAPP)," Journal of Crystal Growth, vol. 327, no. 1, pp. 133-139, 2011.

[16] V. Vijayan, G. Bhagavannarayana, R. R. Babu, R. Gopalakrishnan, K. K. Maurya, and P. Ramasamy, "A comparative study on solution- and Bridgman-grown single crystals of benzimidazole by high-resolution X-ray diffractometry, fourier transform infrared, microhardness, laser damage threshold, and second-harmonic generation measurements," Crystal Growth and Design, vol. 6, no. 6, pp. 1542-1546, 2006.

[17] I. V. Kityk, A. Fahmi, B. Sahraoui, G. Rivoire, and I. Feeks, "Nitrobenzene as a material for the fast-respond degenerate four-wave mixing," Optical Materials, vol. 16, no. 4, pp. 417-429, 2001.

[18] G. G. S. Dutton, T. I. Briggs, B. R. Brown, and M. E. D. Hillman, "Characterization of dinitroalkyl phenols," Canadian Journal of Chemistry, vol. 31, no. 7, pp. 685-687, 1953.

[19] J. L. Koenig, "Raman spectroscopy of biological molecules: a review," Journal of Polymer Science D, vol. 6, no. 1, pp. 59-177, 1972.

[20] K. Prabha, T. Rajesh Kumar, S. F. Du, M. Vimalan, A. Dayalan, and P. Sagayaraj, "Growth and characterization of a new nonlinear optical barium strontium borate (BSB) single crystal," Materials Chemistry and Physics, vol. 121, no. 1-2, pp. 22-27, 2010.

[21] Bhuvana, K. Periyasamy, Robinson S. Jebas, N. Gopalakrishnan, and T. Balasubramanian, "Development of NLO tunable band gap organic devices for optoelectronic applications," Materials Letters, vol. 61, no. 21, pp. 4246-4249, 2007.

[22] P. C. Thomas, S. Aruna, A. Anuradha, J. Packiam Julius, A. Joseph Arul Pragasam, and P. Sagayaraj, "Growth and characterization of semiorganic NLO crystals of LAHClBr," Crystal Research and Technology, vol. 41, no. 12, pp. 1231-1235, 2006.

[23] J. C. Anderson, Dielectrics, Chapman and Hall, 1964.

[24] M. Vimalan, A. Ramanand, and P. Sagayaraj, "Synthesis, growth and characterization of 1-alaninium oxalate: a novel organic NLO crystal," Crystal Research and Technology, vol. 42, no. 11, pp. 1091-1096, 2007. 

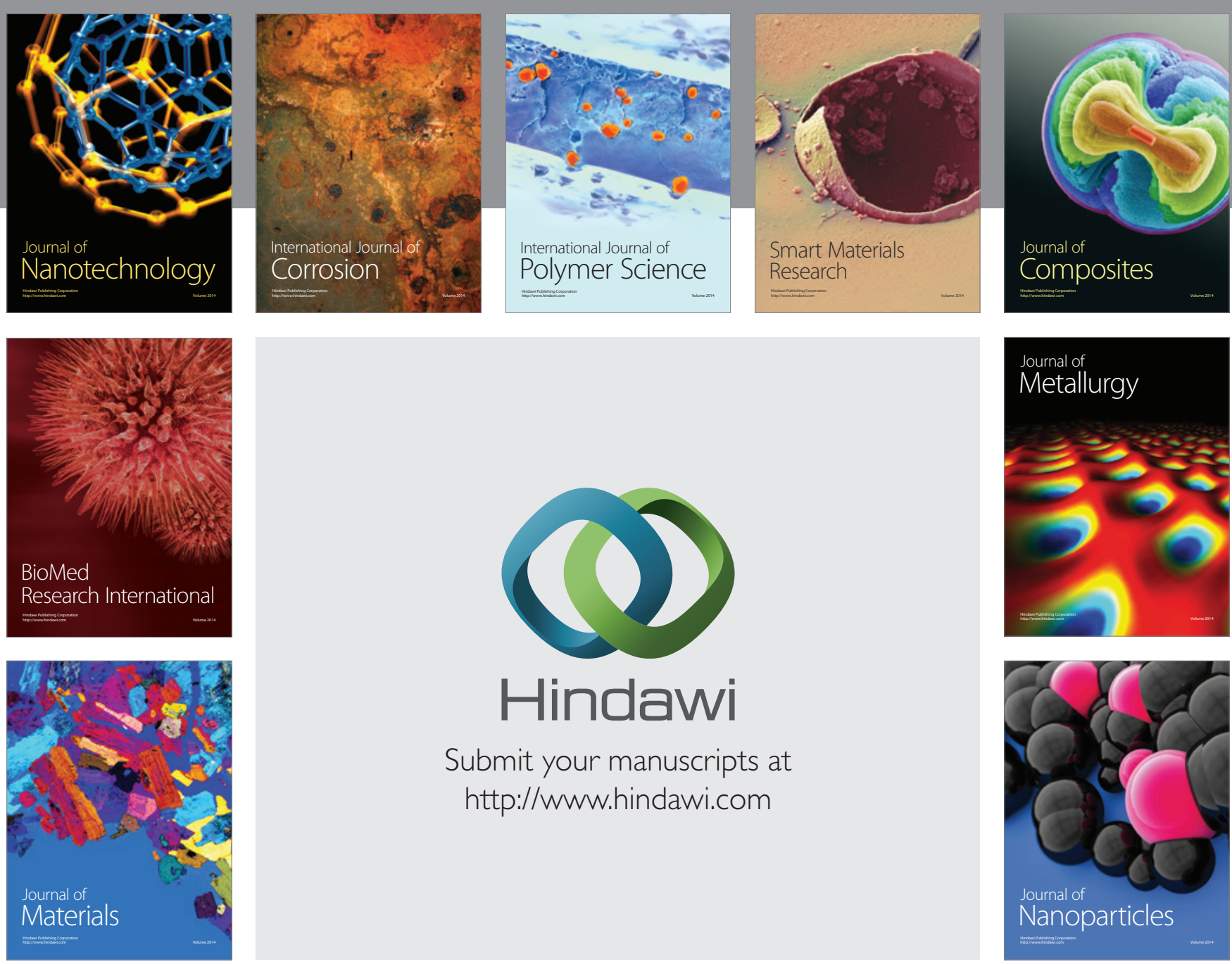

Submit your manuscripts at http://www.hindawi.com
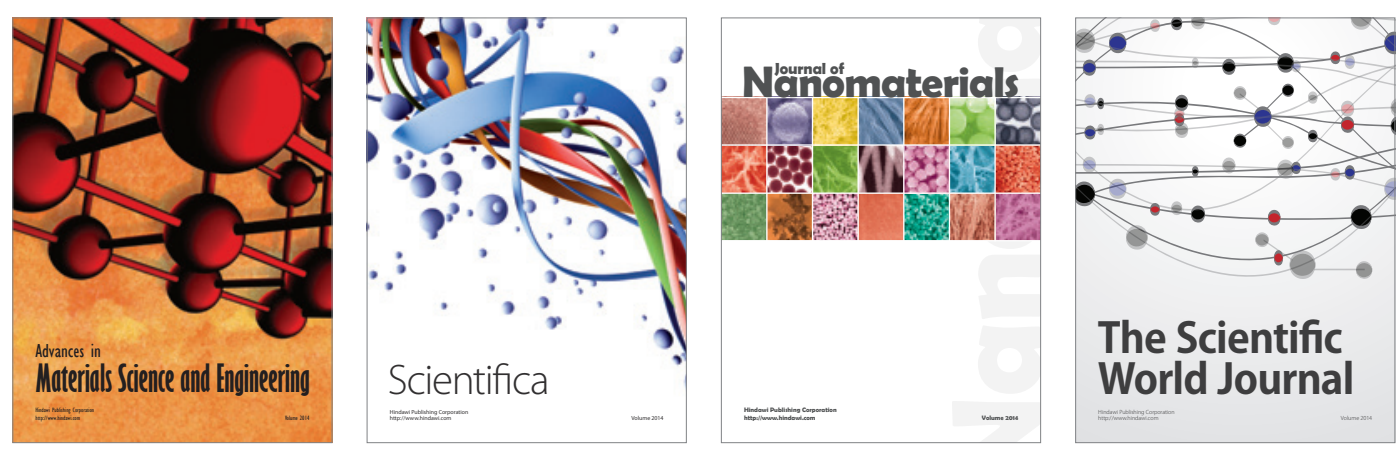

\section{The Scientific World Journal}
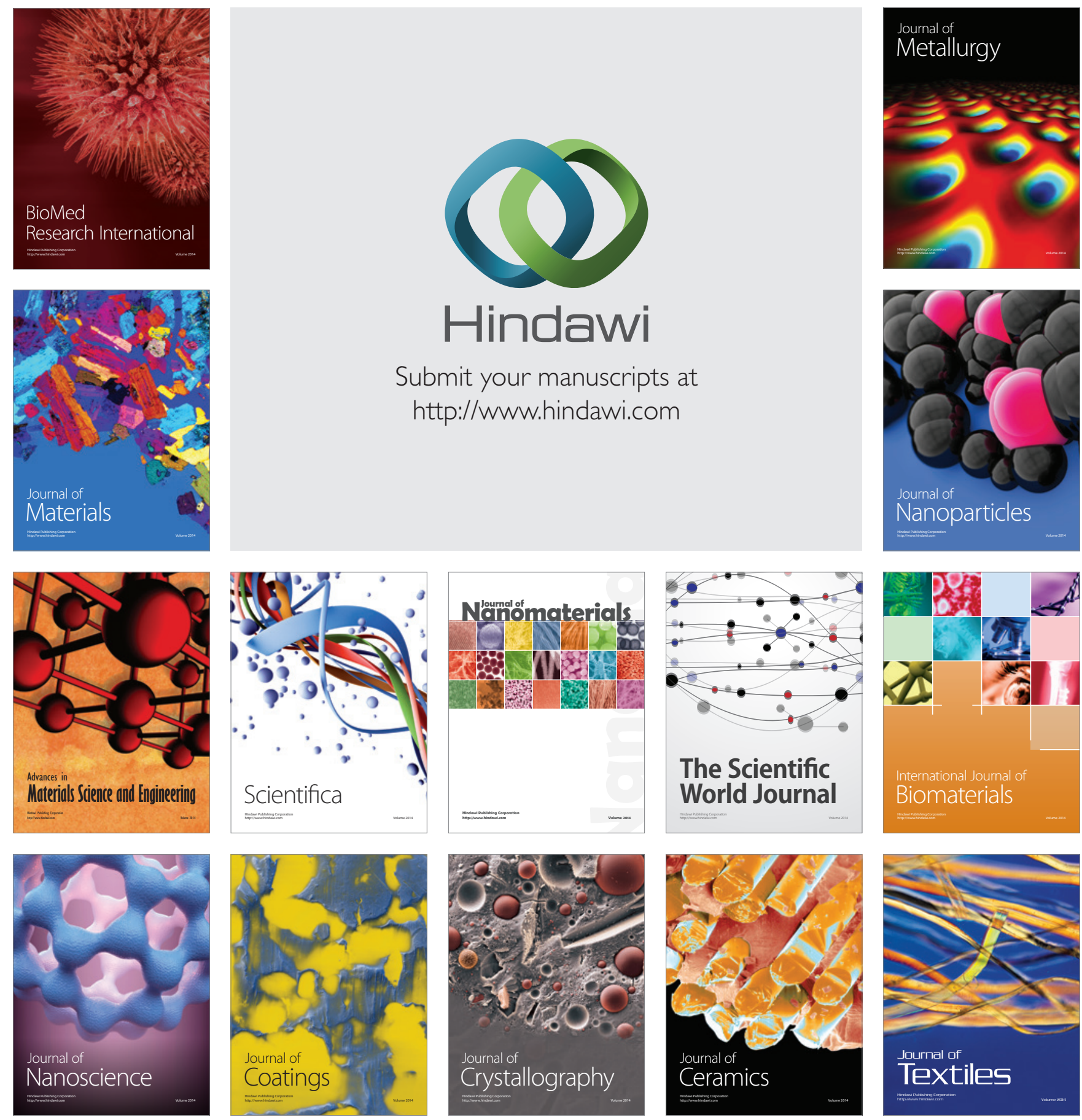